\title{
BMJ Open Prevalence of diabetes, pre-diabetes and associated risk factors: second National Diabetes Survey of Pakistan (NDSP), 2016-2017
}

\author{
Abdul Basit, ${ }^{1}$ Asher Fawwad, ${ }^{2,3}$ Huma Qureshi, ${ }^{4}$ A S Shera, ${ }^{5}$ NDSP Members
}

To cite: Basit A, Fawwad A, Qureshi $\mathrm{H}$, et al. Prevalence of diabetes, pre-diabetes and associated risk factors: second National Diabetes Survey of Pakistan (NDSP), 2016-2017. BMJ Open 2018;8:e020961. doi:10.1136/ bmjopen-2017-020961

Received 3 December 2017 Revised 12 June 2018 Accepted 3 July 2018

Check for updates

(C) Author(s) (or their employer(s)) 2018. Re-use permitted under CC BY-NC. No commercial re-use. See rights and permissions. Published by BMJ.

${ }^{1}$ Department of Medicine, Baqai Institute of Diabetology and Endocrinology, Baqai Medical University, Karachi, Sindh,

Pakistan

${ }^{2}$ Department of Research, Baqai Institute of Diabetology and Endocrinology, Baqai Medical University, Karachi, Sindh, Pakistan

${ }^{3}$ Department of Biochemistry, Baqai Medical University, Karachi, Sindh, Pakistan

${ }^{4}$ Director, Pakistan Health Research Council, Islamabad, Pakistan

${ }^{5}$ Secretary General, Diabetic Association of Pakistan and WHO Collaborating Centre, Karachi, Sindh, Pakistan

Correspondence to

Professor Abdul Basit; abdulbasit@bide.edu.pk

\section{ABSTRACT}

Objective The second National Diabetes Survey of Pakistan (second NDSP) was planned to ascertain the updated prevalence of diabetes, pre-diabetes and associated risk factors at the national and provincial levels. Research design and methods The survey was conducted by using multistage clustering technique in all four provinces of Pakistan from February 2016 to August 2017. An estimated sample size of 10800 was calculated using probability sampling and multistage stratified sampling technique. Twenty-seven clusters were selected out of total 213 clusters from all four provinces (strata) of Pakistan. A total of 46 subclusters were selected by using the 'Rule of thumb'. Out of 12486 targeted individuals, 10834 study subjects finally participated in the study (87\% response rate). Seventeen trained teams collected data using the structured questionnaire. The clinical and anthropometric measurements included height, weight, blood pressure, waist circumference and waist-to-hip ratio while the blood tests included Oral Glucose Tolerance Test (OGTT), haemoglobin A1c and fasting lipid profiles. WHO criteria were used for the diagnosis of diabetes and prediabetes.

Results Overall weighted prevalence of diabetes was $26.3 \%$, of which $19.2 \%$ had known diabetes, and $7.1 \%$ were newly diagnosed people with diabetes. Prevalence of diabetes in urban and rural areas was $28.3 \%$ and $25.3 \%$, respectively. Prevalence of pre-diabetes was $14.4 \%$ (15.5\% in urban areas and $13.9 \%$ in rural areas). Age greater than or equal to 43 years, family history of diabetes, hypertension, obesity and dyslipidaemia were significant associated risk factors for diabetes.

Conclusion The findings of the 2nd NDSP imply that diabetes has reached epidemic proportion and urgently need national strategies for early diagnosis and effective management as well as cost-effective diabetes primary prevention programme in Pakistan.

\section{INTRODUCTION}

The epidemic of diabetes is one of the most alarming public health issues of the 21st century, especially for lower middle-income countries. ${ }^{1}$ It was predicted that from 2010 to 2030 , there will be a $67 \%$ increase in the prevalence of diabetes in these countries. ${ }^{2}$

\section{Strengths and limitations of this study}

To our knowledge, this is the largest survey on diabetes in Pakistan to include all the four provinces and both urban and rural populations.

- Proper epidemiological methods with multistage stratified sampling technique were used to conduct the survey.

- Oral Glucose Tolerance Test and haemoglobin A1c were done for the diagnosis of diabetes for a sample of over 10000 people.

- Apart from diabetes, prevalence of obesity, hypertension and dyslipidaemia was also estimated through this survey.

- We excluded individuals less than 20 years of age as the survey mainly was designed for the diagnosis of type 2 diabetes. However, we would not be able to differentiate between type 1 and type 2 diabetes on the basis of this survey.

Diabetes-related complications are the major cause of premature deaths in the world, ${ }^{3} 4$ with a death occurring in every $6 \mathrm{~s}$ due to the consequences of diabetes. ${ }^{45}$ In 2015, approximately five million diabetes-related deaths were reported in low-income and middle-income countries. $^{46}$

The first National Diabetes Survey of Pakistan (1st NDSP) was done by the Diabetic Association of Pakistan (DAP) in collaboration with WHO between 1994 and $1998 .^{7-11}$ Overall, glycaemic dysregulation (diabetes plus pre-diabetes) was reported to be $22.04 \%$ and $17.15 \%$ in urban and rural areas, respectively, by the 1 st NDSP. $^{7}$ The prevalence of diabetes as assessed by fasting plasma glucose had doubled from $7.2 \%$ in 2002 to $14.2 \%$ in 2009 in the rural areas of Baluchistan. ${ }^{12}$ Similarly, the prevalence of impaired fasting glucose (IFG) has risen from $6.5 \%$ to $11 \% .^{12}$ Furthermore, studies conducted in school-age children had also warned of a rise in childhood obesity. ${ }^{13}$ Pakistan Health Research Council (PHRC) conducted a 
questionnaire-based survey using STEPS, a 'WHO STEPwise approach to surveillance', in the provinces of Punjab and Sindh. ${ }^{14}$ This survey along with other studies reported the prevalence of diabetes between $13.1 \%$ and $26.9 \% .^{12-16}$ Hence the epidemic of diabetes was predicted nearly a decade ago. Most of these studies had been smaller scale, focusing on specific towns or villages and because of diversified ethnic groups within Pakistani population, could not accurately reflect the prevalence of diabetes in Pakistan. Therefore, there was a need for a repeat survey, that is, second NDSP.

This led to a joint collaboration of Ministry of National Health Services, Regulation and Coordination, PHRC, DAP and Baqai Institute of Diabetology and Endocrinology, Baqai Medical University, to conduct the second NDSP. The aim of this survey is to ascertain prevalence of diabetes, pre-diabetes and associated risk factors at the national and provincial levels. The results are expected to explore ethnic and geographical variation in diabetes and pre-diabetes phenotypes.

\section{RESEARCH DESIGN AND METHODS}

The second NDSP was conducted from February 2016 to August 2017 in all four provinces of Pakistan, that is, Punjab, Sindh, Khyber Pakhtunkhwa and Baluchistan.

Pakistani nationals aged 20 years or more were included in the survey, whereas pregnant women and those not residents of the selected households were excluded. An estimated sample size of 10800 was calculated using probability sampling and multistage stratified sampling techniques. ${ }^{17}$ Sample size was calculated based on an expected prevalence of $18 \%$ (based on previous surveys), level of significance $97 \%$, margin of error $1 \%$ with a design effect of 2 , considering complex multistage design.

Stratification of population was done on the basis of urban and rural domains for all four provinces as defined in the latest available census. ${ }^{18}$ Each province was considered as a stratum and the districts (geographical subdivision of provinces legally described by government) considered as clusters were selected from each stratum. Tehsils or towns (further bifurcation of districts legally described by government) considered as subclusters were selected from each identified cluster for the survey.

Clusters and subclusters were randomly selected using probability proportional to size technique, and number of clusters were selected from each province using the 'rule of thumb' number of clusters $(\mathrm{k})=($ sample size of stratum $/ 2)^{0.5} \cdot{ }^{19}$ Twenty-seven clusters were selected out of a total 213 clusters from all over Pakistan. A total of 46 subclusters (21 from urban and 25 from rural) were selected (figure 1).

Seventeen teaching hospitals and/or diabetes centres participated in the second NDSP. The training sessions of these 17 teams were conducted from February 2016 to July 2016. The teams were trained to identify households, to fill the questionnaire, to take anthropometric and clinical measurements and to collect blood samples. The questionnaire was adopted from the WHO Questionnaire used in the 1st NDSP. ${ }^{8}$ Each team was led by a physician as provincial coordinator of that cluster and each team comprised laboratory technicians, paramedical staff and survey officers.

Door-to-door assessment was done following systematic sampling technique. The first household in the lane was selected randomly and afterwards every 10th house was identified. In case residents of the identified household were not present or if they refused to participate, the next consecutive household was taken. Teams marked the houses and informed the adult residents. The selected household members were requested to come after an overnight fast (at least 8 hours) to the camp on the specific day. Two hundred and fourteen camps were conducted to recruit the required number of study subjects. Each participant was expected to stay within the screening facility for at least 2 hours, that is, for the post $75 \mathrm{~g}$ anhydrous glucose load. Meanwhile, the anthropometric and clinical data were collected by the trained paramedic staff under the supervision of the provincial coordinator.

\section{Behavioural and social assessment}

For each participant, we administered a detailed behavioural and social assessment with the help of a predesigned questionnaire. All information was gathered through one-to-one interviews by a trained survey officer. Tobacco users were defined as self-reported smoking and chewing of tobacco products daily irrespective of quantity consumed and duration.

\section{Anthropometric and clinical assessment}

Height, bodyweight, waist circumference and blood pressure were measured using standardised techniques. ${ }^{20}$ Weight was taken to the nearest of $0.1 \mathrm{~kg}$ with participants in light clothes and without shoes. Height was recorded to the nearest of $0.1 \mathrm{~cm}$, while subjects standing in erect posture vertically touching the occiput, back, hip and heels on the wall. Body mass index (BMI) was calculated as weight in kilograms divided by height in metre squared $\left(\mathrm{kg} / \mathrm{m}^{2}\right)$. Waist circumference and hip circumference were measured between the centre point of the lower margin of the ribs and iliac crest the mid-point. Blood pressure was measured with mercury sphygmomanometer. Individuals were requested to take $10 \mathrm{~min}$ rest in a sitting position before measurement of blood pressure to reduce variation. Mean of two readings was taken.

\section{BIOCHEMICAL ASSESSMENT}

Blood samples were collected by using sterilised disposable vacutainer tubes containing sodium fluoride (for glucose), EDTA K2 (for haemoglobin A1c; HbA1c) and gel (for lipids). Within 1 hour of blood collection, the samples were centrifuged, separated and sent to the laboratory. Plasma glucose was measured using the glucose oxidase peroxidase method, total cholesterol 


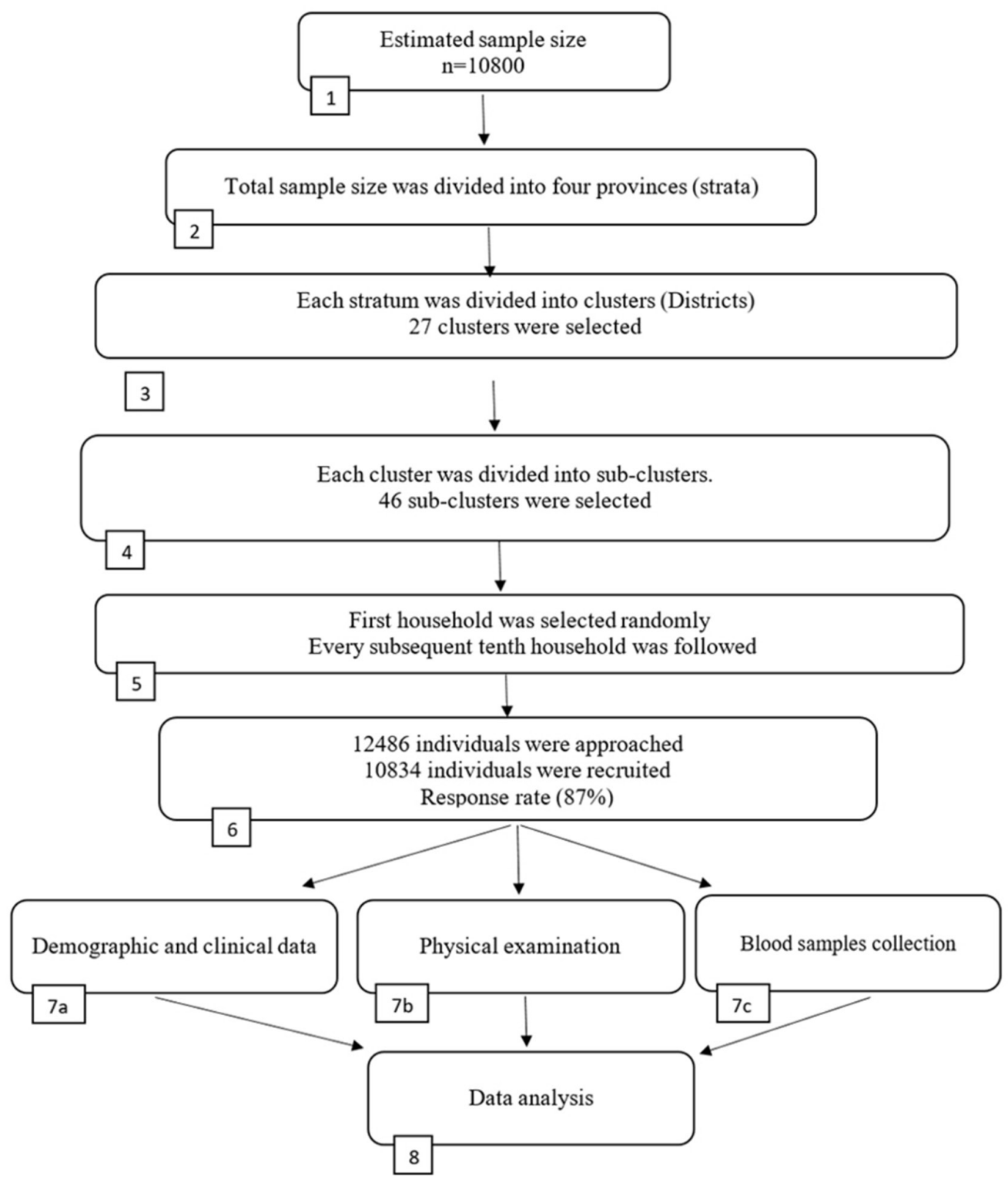

Figure 1 Step-by-step approach for the National Diabetes Survey of Pakistan.

by cholesterol oxidase phenol 4-aminoantipyrine peroxidase (CHOD-PAP) method, triglycerides by glycerol phosphate oxidase-p-aminophenazone (GPOPAP) method, high-density lipoprotein cholesterol (HDL-C) by homogeneous enzymatic calorimetric method, low-density lipoprotein cholesterol (LDL-C) by CHOD-PAP method and HbA1c by high-performance liquid chromatography method. ${ }^{21}$ Plasma glucose was performed both fasting and 2 hours post $75 \mathrm{~g}$ glucose load (2-hour PGL) at the designated laboratory close to the survey site with the specified methodology. Samples for HbAlc and lipid profile were transported as per the standardised protocol ${ }^{22}$ to PHRC, Jinnah Postgraduate Medical Centre, Karachi, for analysis. Equipment with same specifications was used throughout the study for standardisation and as a measure of quality assurance. Calibration and controls were run as per the specified guidelines. ${ }^{22}$
Interassay and intra-assay coefficients of variability for these biochemical parameters were within the acceptable ranges.

\section{Diagnostic criterion}

WHO definition was used to diagnose diabetes and pre-diabetes (intermediate hyperglycaemia). Results of plasma glucose testing were categorised as follows: isolated IFG was defined as fasting plasma glucose level between $110 \mathrm{mg} / \mathrm{dL}$ and $125 \mathrm{mg} / \mathrm{dL}$ with 2-hour PGL $\leq 140 \mathrm{mg} / \mathrm{dL}$. Isolated impaired glucose tolerance was defined as fasting glucose level $<110 \mathrm{mg} / \mathrm{dL}$ and 2-hour PGL between $141 \mathrm{mg} / \mathrm{dL}$ and $199 \mathrm{mg} / \mathrm{dL}$. Newly diagnosed diabetes was defined as fasting plasma glucose level $\geq 126 \mathrm{mg} / \mathrm{dL}$ or 2 -hour PGL $\geq 200 \mathrm{mg} / \mathrm{dL}$ or both. ${ }^{23}$ Known diabetes was considered if the subject had been diagnosed as diabetic by a physician. 
Table 1 Baseline characteristics of the study participants, by province urban and rural areas of Pakistan

\begin{tabular}{|c|c|c|c|c|c|}
\hline & Punjab & Sindh & $\begin{array}{l}\text { Khyber } \\
\text { Pakhtunkhwa }\end{array}$ & Baluchistan & Overall \\
\hline Number of participants & 6221 & 2531 & 1544 & 538 & 10834 \\
\hline Age (years) & $43.5 \pm 14.1$ & $45.5 \pm 14.2$ & $40.3 \pm 12.9$ & $48.4 \pm 12.81$ & $43.8 \pm 14.0$ \\
\hline \multicolumn{6}{|l|}{ Gender } \\
\hline Male & $2457(39.5)$ & $1192(47.1)$ & $835(54.1)$ & $257(47.8)$ & $4756(43.9)$ \\
\hline Female & $3764(60.5)$ & $1339(52.9)$ & 709 (45.9) & $281(52.2)$ & $6078(56.1)$ \\
\hline Primary education or more & 2675 (49.6) & $1353(61.3)$ & $759(55.6)$ & $278(54.9)$ & $5065(53.5)$ \\
\hline Tobacco addiction & $614(11.2)$ & $493(22.2)$ & $117(8.9)$ & $152(29.1)$ & $1376(14.5)$ \\
\hline Positive family history of diabetes & $1509(27.8)$ & $760(37)$ & $240(22.2)$ & $236(43.9)$ & $2745(30.2)$ \\
\hline \multirow[t]{2}{*}{${ }^{*}$ Body mass index $\left(\mathrm{kg} / \mathrm{m}^{2}\right)$} & $27.5 \pm 6.1$ & $26.5 \pm 5.6$ & $27.2 \pm 6.1$ & $26.7 \pm 5.0$ & $27.2 \pm 6.0$ \\
\hline & $27.0(23.3-31.2)$ & $25.9(22.6-29.6)$ & $26.4(23.4-30.1)$ & $25.6(23.5-29.2)$ & $26.6(23.1-30.5)$ \\
\hline \multicolumn{6}{|l|}{ *Waist circumference $(\mathrm{cm})$} \\
\hline \multirow[t]{2}{*}{ Male } & $91.7 \pm 14.5$ & $92.3 \pm 12.1$ & $98.0 \pm 12.4$ & $96.7 \pm 11.7$ & $93.1 \pm 13.8$ \\
\hline & $91.0(82-101)$ & $93(84-100)$ & $98(89-106)$ & $97(91-100)$ & $93(85-102)$ \\
\hline \multirow[t]{2}{*}{ Female } & $92.4 \pm 15.0$ & $94.3 \pm 13.4$ & $82.3(11.7)$ & $101.1 \pm 15.6$ & $93.2 \pm 14.5$ \\
\hline & $92(81-103)$ & $95(86-103)$ & $81(75-88)$ & $97(91-112)$ & $93(82-103)$ \\
\hline \multicolumn{6}{|l|}{ Blood pressure $(\mathrm{mm} \mathrm{Hg})$} \\
\hline$<140 / 90$ & $2482(45 \%)$ & $958(44.9 \%)$ & $922(65.5 \%)$ & $187(34.9 \%)$ & $4549(47.4 \%)$ \\
\hline$\geq 140 / 90$ & 3032 (55\%) & 1178 (55.1\%) & $486(34.5 \%)$ & $349(65.1 \%)$ & 5045 (52.6\%) \\
\hline
\end{tabular}

Data are presented as mean \pm SD or $\mathrm{n}(\%)$.

${ }^{*}$ Median (IQR).

For the diagnosis of diabetes using HbA1c as diagnostic tool, the American Diabetes Association (ADA) standards of care were used. HbAlc $\geq 6.5 \%(48 \mathrm{mmol} / \mathrm{mol})$ was diagnosed as diabetic while HbA1c between $5.7 \%$ and $6.4 \%$ (39 and $46 \mathrm{mmol} / \mathrm{mol}$ ) was considered as pre-diabetes. ${ }^{24}$

People were considered hypertensive if they were already diagnosed by a physician or if they were taking any antihypertensive medication or if the systolic blood pressure was $\geq 140 \mathrm{~mm} \mathrm{Hg}$ and/or diastolic blood pressure $\geq 90 \mathrm{~mm} \mathrm{Hg} .{ }^{8}$

As per WHO Asia Pacific Guidelines, obesity was defined as a BMI of $25 \mathrm{~kg} / \mathrm{m}^{2}$ or higher for both males and females with or without abdominal obesity. ${ }^{25}$ Central obesity was defined as waist circumference $\geq 90 \mathrm{~cm}$ and $\geq 80 \mathrm{~cm}$ in males and females, respectively. ${ }^{89}$

Using the Adult Treatment Panel III guidelines, dyslipidaemia was classified as one or more of the following conditions in fasting state: serum cholesterol $>200 \mathrm{mg}$ / dL, serum LDL-C $>130 \mathrm{mg} / \mathrm{dL}$, serum HDL-C $<40 \mathrm{mg} /$ $\mathrm{dL}$ and $<50 \mathrm{mg} / \mathrm{dL}$ for male and female, respectively, and serum triglycerides $>150(\mathrm{mg} / \mathrm{dL}) .{ }^{26}$ People were also considered as dyslipidaemic if they were taking any lipid-lowering medications.

\section{PATIENT AND PUBLIC INVOLVEMENT}

It is a community-based epidemiological survey conducted to ascertain the prevalence of people with type 2 diabetes in Pakistan. The results of this survey will help the National and International stakeholders to take appropriate measures for prevention of diabetes at all levels. With the informed consent, 10834 individuals from all four provinces of Pakistan were involved in the survey. The participation of the study subjects was limited to the collection of study data approved by the ethical review committee while the whole survey was performed by the survey team members. The tests involved in the survey were conducted free of cost and the results were communicated to study participants as printed medical reports through local NDSP team members. Complimentary medical consultation was provided in case of any abnormal finding. Subjects with newly diagnosed diabetes and impaired glucose tolerance were referred to the nearest centre for registration and treatment.

\section{STATISTICAL ANALYSIS}

Data analysis was conducted on SPSS V.20. Descriptive analysis included the estimation of mean values and SDs for continuous variables. Categorical variables and prevalence values were presented in the form of frequency and percentage. For calculating the prevalence of diabetes, the following formula was used ${ }^{27}$ :

$$
\begin{aligned}
\mathrm{P} & =\left(\frac{\text { Sample size of district }}{\text { Sample size of province }}\right) \\
& \times\left(\frac{\text { Number of diabetics from that district }}{\text { Number of individuals sampled from that district }}\right)
\end{aligned}
$$


Table 2 Weighted prevalence of diabetes and pre-diabetes, by province urban and rural areas of Pakistan

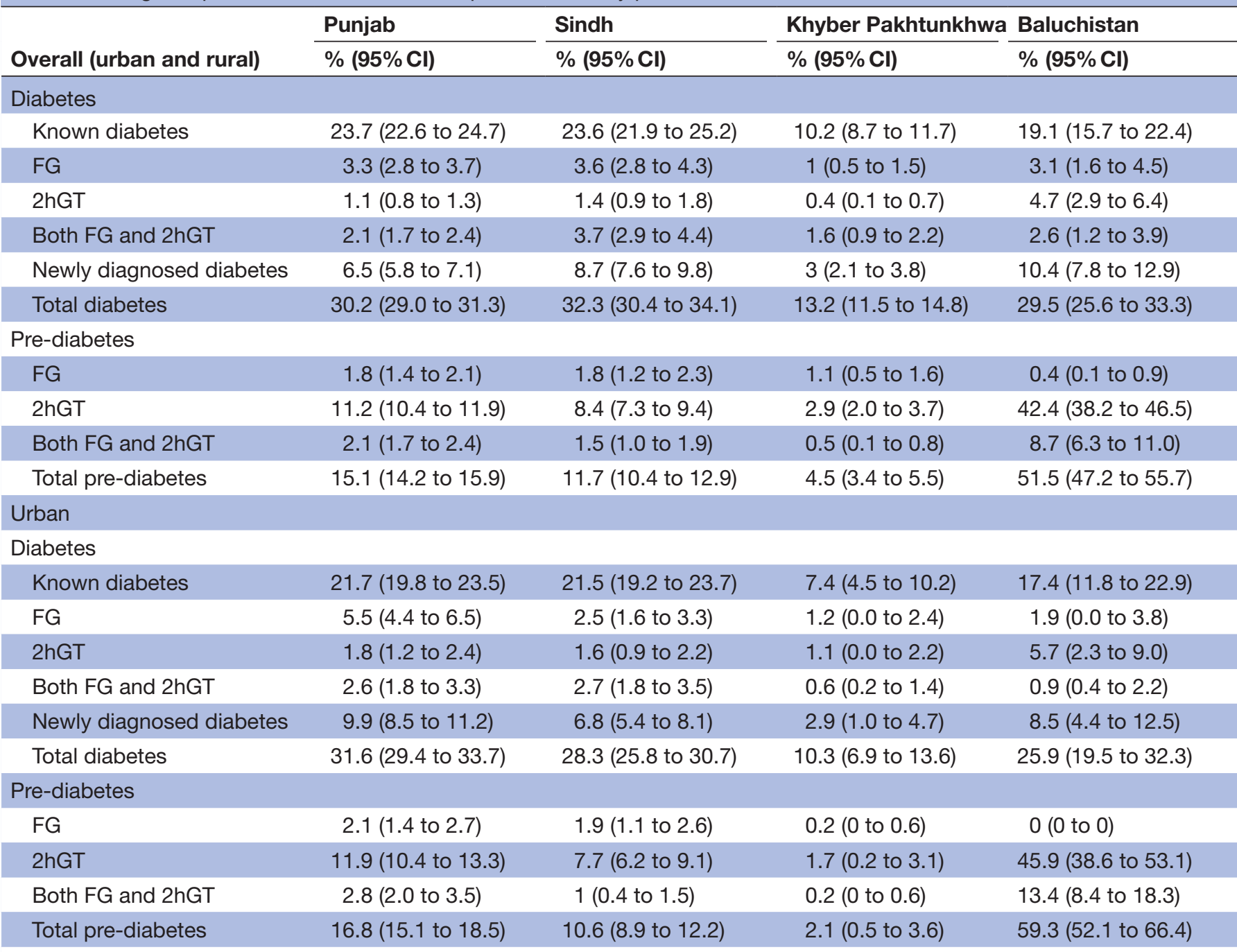

Rural

Diabetes

\begin{tabular}{lcccc} 
Known diabetes & $21.4(20.1$ to 22.6$)$ & $19.4(17.0$ to 21.7$)$ & $10.3(8.5$ to 12.0$)$ & $15.1(11.3$ to 18.8$)$ \\
\hline FG & $2.3(1.8$ to 2.7$)$ & $6.4(4.9$ to 7.8$)$ & $1.7(0.9$ to 2.4$)$ & $5.1(2.8$ to 7.3$)$ \\
2hGT & $0.6(0.3$ to 0.8$)$ & $1.5(0.7$ to 2.2$)$ & $0.7(0.2$ to 1.1$)$ & $5.7(3.3$ to 8.1$)$ \\
Both FG and 2 hGT & $1.7(1.2$ to 2.1$)$ & $4.8(3.5$ to 6.0$)$ & $2.7(1.7$ to 3.6$)$ & $4.4(2.2$ to 6.5$)$ \\
Newly diagnosed diabetes & $4.6(3.9$ to 5.2$)$ & $12.7(10.7$ to 14.6$)$ & $5.1(3.8$ to 6.3$)$ & $15.2(11.4$ to 18.9$)$ \\
Total diabetes & $26(24.6$ to 27.3$)$ & $32.1(29.3$ to 34.8$)$ & $15.4(13.3$ to 17.4$)$ & $30.2(25.4$ to 34.9$)$ \\
Pre-diabetes & & & & \\
FG & $1.4(1.0$ to 1.7$)$ & $1.6(0.8$ to 2.3$)$ & $1.7(0.9$ to 2.4$)$ & $0.3(0.0$ to 0.8$)$ \\
2hGT & $10.7(9.7$ to 11.6$)$ & $9.1(7.3$ to 10.8$)$ & $4.4(3.2$ to 5.5$)$ & $37.1(32.0$ to 42.1$)$ \\
Both FG and 2hGT & $1.4(1.0$ to 1.7$)$ & $2.2(1.3$ to 3.0$)$ & $0.9(0.3$ to 1.4$)$ & $6.4(3.8$ to 8.9$)$ \\
\hline Total pre-diabetes & $13.5(12.4$ to 14.5$)$ & $12.9(10.9$ to 14.8$)$ & $7(5.5$ to 8.4$)$ & $43.8(38.6$ to 48.9$)$ \\
\hline
\end{tabular}

OGTT criteria for diagnosis of diabetes: fasting $\geq 126 \mathrm{mg} / \mathrm{dL}$ and $/$ or 2 hours $\geq 200 \mathrm{mg} / \mathrm{dL}$.

OGTT criteria for diagnosis of pre-diabetes: fasting 110-125 mg/dL and/or random blood sugar (RBS) 140-199 mg/dL.

2hGT, 2-hour glucose tolerance; FG, fasting glucose.

Associated risk factors of diabetes, pre-diabetes, hypertension, obesity and dyslipidaemia were investigated using multivariable logistic regression.
Univariate logistic regression was carried out to select potential predictors $(\mathrm{p} \leq 0.25)$. Multivariate logistic regression analyses were undertaken to estimate the 


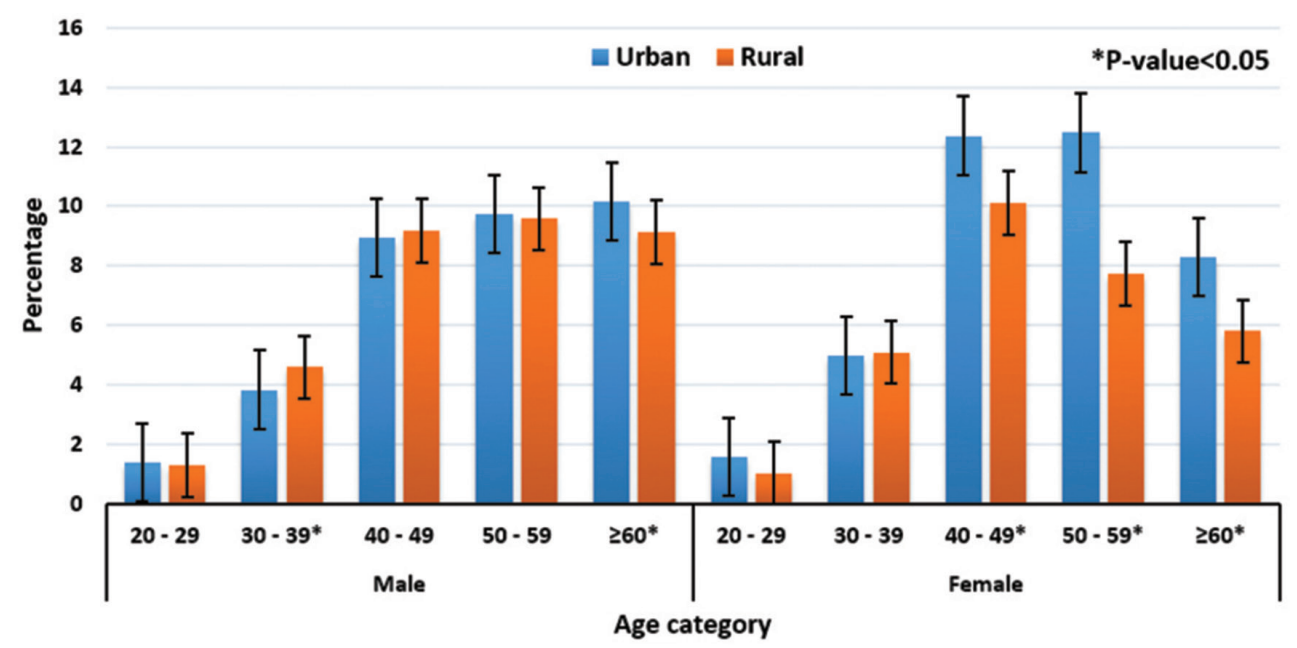

Figure 2 Age-stratified prevalence of diabetes among men and women with urban and rural distribution.

independent effect of predictors on the prevalence of diabetes and pre-diabetes. Models were built and compared by stepwise forward selection method and likelihood ratio test.

Multicollinearity for variables was checked using variance inflation factor (VIF) with a cut-off point mean VIF $>10$. Goodness of fit for the final fitted model was checked using the Hosmer and Lemeshow test. Association between predictors and occurrence of diabetes and pre-diabetes was summarised using adjusted OR and statistical significances were tested at $p<0.05$. Final model equation was written as:

$$
\mathrm{g}_{0}\left(\mathrm{t}, \mathrm{X}_{1}, \mathrm{X}_{2}, \ldots, \mathrm{X}_{\mathrm{k}}\right)=\mathrm{g}_{0}(\mathrm{t}) \exp \left(\sum_{i=1}^{k} \beta \mathrm{i} \mathrm{Xi}\right)
$$

For all estimates, the study population was weighted to the latest available demographic information at Pakistan Bureau of Statistics. ${ }^{18}$

\section{RESULTS}

In this survey, 12486 individuals were approached, out of which 10834 individuals finally participated in the study (87\% response rate). Basic characteristics of the study population are presented in table 1 . A total of 10834 subjects were screened for diabetes; $43.9 \%$ were males and $56.1 \%$ were females. More than half of all the participants $(53.5 \%)$ had at least primary level education. Around one-third $(30 \%)$ of the population had positive family history of diabetes, and $14.5 \%$ were tobacco users. Mean BMI of participants was almost similar in all provinces of Pakistan with an overall mean of $27.23 \pm 6.0 \mathrm{~kg} / \mathrm{m}^{2}$ $($ mean \pm SD).

According to OGTT criteria, overall age-adjusted weighted prevalence of diabetes was $26.3 \%$, of which $19.2 \%$ had known diabetes and $7.1 \%$ were newly diagnosed people with diabetes. Prevalence of diabetes in urban and rural areas was $28.3 \%$ and $25.3 \%$, respectively. Highest prevalence of diabetes was observed in Sindh followed by Punjab. Prevalence of pre-diabetes was $14.4 \%$, urban and rural distribution was $15.5 \%$ and $13.9 \%$, respectively. Overall glycaemic dysregulation (diabetes, plus pre-diabetes) was $43.8 \%$ and $39.2 \%$ in urban and rural areas, respectively. Prevalence of pre-diabetes and

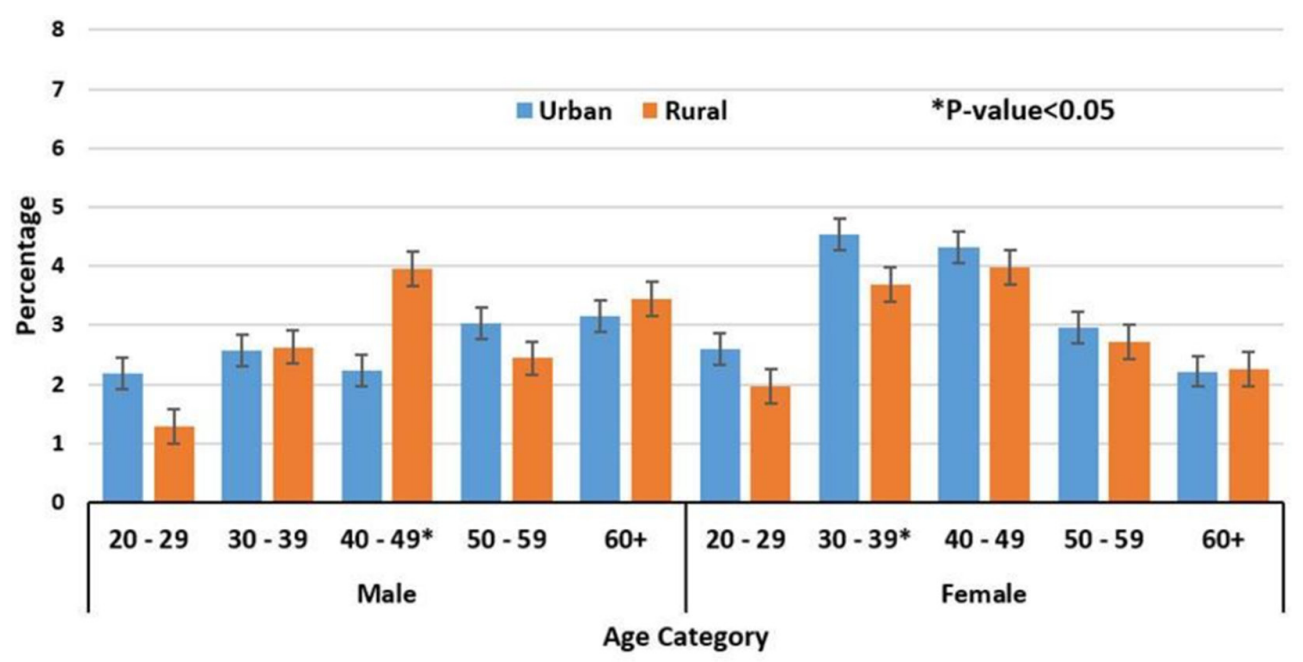

Figure 3 Age-stratified prevalence of pre-diabetes among men and women with urban and rural distribution. 
newly diagnosed diabetes was higher in Baluchistan compared with other provinces (table 2). According to the ADA standards of care, on the basis of HbAlc criteria, prevalence of diabetes and pre-diabetes was $30.1 \%$ and $5.9 \%$, respectively.

Urban women showed significantly higher prevalence of diabetes than rural women above the age of 40 years while in men this trend was seen in the age group of 60 years and above $(\mathrm{p}<0.05)$. On the other hand, urban men in the age group 30-39 years showed significantly $(\mathrm{p}<0.05)$ lower prevalence of diabetes than rural men (figure 2).

Rural men showed significantly higher prevalence of pre-diabetes than urban men for the age group of 40-49 years while for women significant difference was seen in urban compared with rural population for the age group of 30-39 years (figure 3 ).

Table 3 shows the multivariable logistic regression for identifying the associated risk factors for diabetes, pre-diabetes, hypertension, obesity and dyslipidaemia. Age ( $\geq 43$ years), family history of diabetes, hypertension, obesity and dyslipidaemia were significant risk factors for diabetes $(p \leq 0.0001)$. Similar were the risk factors for pre-diabetes including education with the exception of obesity $(p \leq 0.05)$. Significant association was found between diabetes, hypertension, obesity and dyslipidaemia $(\mathrm{p} \leq 0.05)$.

\section{DISCUSSION}

We estimated the overall age-adjusted weighted prevalence of diabetes and pre-diabetes as $26.3 \%$ and $14.4 \%$, respectively. Overall glycaemic dysregulation, that is, diabetes plus and pre-diabetes was $43.8 \%$ and $39.3 \%$ in urban and rural areas, respectively. This suggests doubling of glycaemic dysregulation compared with the 1st NDSP done during 1994-1998. ${ }^{7}$

Our study has several strengths. To our knowledge, this is the largest survey on diabetes in Pakistan to include all the four provinces and both urban and rural populations. Proper epidemiological methods with multistage stratified sampling technique were used. Oral GTT and HbA1c were done for the diagnosis of diabetes for a sample of over 10000 people. Another strength is that the whole study was completed within 1 year with the help of 17 teams across the country. There are also some limitations in our study. According to WHO, ideally blood tests shall be repeated for the diagnosis of diabetes, but we were not able to conduct the repeat specimen collection because of resource constraints. We also excluded individuals less than 20 years of age as the survey mainly was designed for the diagnosis of type 2 diabetes. Furthermore, we would not be able to differentiate between type 1 and type 2 diabetes on the basis of our survey. This is because diagnostic approach for type 1 diabetes entails different methodological processes which were beyond the scope of our study. 
Various regional surveys have shown higher prevalence of diabetes among Indo-Asians compared with other ethnic groups which support our findings. The prevalence of diabetes in Malaysia was 22.9\% but among Indians residing in Malaysia, its prevalence was $37.9 \%{ }^{28}$ In addition, studies from Bangladesh and Turkey had also shown similar results. ${ }^{29}{ }^{30} \mathrm{~A}$ recent study from China showed that $11.6 \%$ adults ( $\geq 18$ years) had diabetes and almost $50 \%$ of the population had pre-diabetes. ${ }^{31}$ Similarly, a recent study from 15 states of India showed that $7.3 \%$ had diabetes and $10.3 \%$ of the population had pre-diabetes. ${ }^{32}$ Also worth noting is the prevalence of diabetes in the UK which had doubled from $2.39 \%$ in 2000 to $5.32 \%$ in $2013 .{ }^{33}$ Moreover, the prevalence of pre-diabetes had increased from $11.6 \%$ in 2003 to $35.3 \%$ in $2011 .^{34}$

In our study, it was noted that in three out of four provinces, the prevalence of diabetes was higher than the prevalence of pre-diabetes. The age and gender-weighted prevalence also suggests that in early years pre-diabetes is higher but diabetes prevalence rises steeply after the age of 30 . The possible explanation is the rapid transition to diabetes from pre-diabetes in these provinces. Whereas, in the province of Baluchistan, diabetes to pre-diabetes ratio is almost 1:2, suggesting that a large number of individuals are at risk of developing type 2 diabetes.

Prevalence of diabetes on the basis of HbAlc was slightly more than on the basis of OGTT. However, prevalence of pre-diabetes was much lower comparatively, that is, $5.9 \%$ by HbAlc criteria compared with $14.4 \%$ OGTT. This pattern has also been found in other studies. ${ }^{35} 36$ Considering limitations of resources and HbA1c variation with anaemia and haemoglobinopathies, we would still take OGTT as a gold standard diagnostic tool in an epidemiological setting.

One of the unanswered questions from the study was much lower prevalence of diabetes and pre-diabetes in the province of Khyber Pakhtunkhwa. On the other hand, diabetes and pre-diabetes were much higher in the province of Baluchistan. A number of smaller studies had already warned of higher prevalence of risk factors leading to diabetes in Baluchistan in the last 20 years, but still this high proportion needs to be evaluated. ${ }^{810} 3738$ Further researches are required to study genetic and environmental influences among various ethnicities.

Also addressed in this survey were parameters like hypertension, obesity and dyslipidaemia in Pakistan. These numbers are also correspondingly high and strongly suggestive of the rise of risk factors leading to diabetes. Hypertension nationally was surveyed by the Pakistan Health and Research Council (previously called Pakistan Medical Research Council) in 1998, and the prevalence of hypertension was reported as $33 \% .{ }^{39}$ In our survey, hypertension in the community is $52.6 \%$. Similar are the results for overweight and obesity. For overweight and obesity, we have chosen the WHO cut-offs, and the prevalence is $62.1 \%$ and $47.5 \%$, respectively, while from Asian cut-offs, these figures are $76.2 \%$ and $62.1 \%$.
This study has tremendous future implications. Diabetes has now become a major public health challenge in Pakistan. If appropriate actions are not taken, the burden of disability and deaths from diabetes will be enormous. The existing infrastructure of healthcare services for managing diabetes and its complications is suboptimal. Poverty both as a cause and consequence of diabetes and its complications is a major threat to health, and economic and social development.

It requires multiple stakeholders including policy-makers to integrate and execute their actions to save millions of people from premature morbidity and mortality. Urgent strategies need to be developed for nationwide network of diabetes care and management. Also, primary prevention ought to be addressed at all levels. More importantly, healthy lifestyle changes must be educated and encouraged at school level. Maternal and child health must be given top priority to prevent transgenerational obesity and diabetes.

\section{CONCLUSION}

The findings of the second NDSP imply that diabetes has reached epidemic proportion and urgently needs national strategies for early diagnosis and effective management, as well as cost-effective diabetes primary prevention programme in Pakistan.

Acknowledgements We acknowledge the support of Research and Laboratory Department of Baqai Institute of Diabetology and Endocrinology (BIDE), Karachi for data management and we would also like to thank Mr Abdul Rashid and Mr Muhammad Sohail from Pakistan Health Research Council (PHRC), Karachi. We are grateful to all study subjects for their participation in the 2nd NDSP.

Collaborators NDSP members (with surnames in alphabetical order): (1) Dr Mujeeb Ur Rehman Abro, Assistant Professor of Medicine, Chandka Medical College, Shaheed Mohtarma Benazir Bhutto Medical University, Larkana, Sindh; (2) Dr Khawaja Ishfaq Ahmed, Ex-PGR, Pakistan Institute of Medical Sciences, Islamabad, Punjab; (3) Dr Khurshid Ahmed, Consultant Physician, Zahid Medical Centre, Hub, Baluchistan; (4) Dr Sobia Sabir Ali, Assistant Professor, Department of Diabetes and Endocrinology, Lady Reading Hospital, Peshawar, Khyber Pakhtunkhwa; (5) Professor Ahmed Bilal, Professor and Head of Medical Department Faisalabad Medical College, Faisalabad, Punjab; (6) Dr Anam Butt, Research Officer, Baqai Institute of Diabetology and Endocrinology, Baqai Medical University, Karachi, Sindh; (7) Professor Bikha Ram Devrajani, Chairman, Department of Medicine and Director Sindh Institute of Endocrinology and Diabetes, Liaquat University of Medical and Health Sciences, Jamshoro, Sindh; (8) Mr ljaz Hayder, Research Officer, Pakistan Health Research Council, Karachi, Sindh; (9) Dr Yasir Humayun, EPI coordinator, DHO Office, Mansehra, Khyber Pakhtunkhwa; (10) Mrs Rabia Irshad, Research Officer, Pakistan Health Research Council, Karachi, Sindh; (11) Dr Riasat Ali Khan, Diabetologist, Canada Medical Group Hospital, Defence, Karachi, Sindh; (12) Dr Asima Khan, Head of Diabetes Department, Sindh Government Hospital, New Karachi, Karachi, Sindh; (13) Dr Aamir Akram Khowaja, Postgraduate Resident, Sindh Government Qatar Hospital, Karachi, Sindh; (14) Dr Raheela Khowaja, Postgraduate Resident, Baqai Institute of Diabetology and Endocrinology, Baqai Medical University, Karachi, Sindh; (15) Professor Qazi Masroor, Professor of Medicine and Head of Department, Quaid-e-Azam Medical College, Bahawalpur, Punjab; (16) Dr Maqsood Mehmood, Head of Department, Fatma tu Zahra Hospital, Gujranwala, Punjab; (17) Mr Hassan Moin, Statistician, Baqai Institute of Diabetology and Endocrinology, Baqai Medical University, Karachi, Sindh; (18) Dr Wasif Noor, Diabetologist, Akhuwat Health Services Diabetes Centre, Lahore, Punjab; (19) Mr Ibrar Rafique, Research Officer, Pakistan Health Research Council, Islamabad, Punjab; (20) Dr Tahir Rasool, Diabetologist, Akhuwat Health Services Diabetes Centre, Lahore, Punjab; (21) Mrs Rubina Sabir, Laboratory Manager, Baqai Institute of Diabetology and Endocrinology, Baqai Medical University, Karachi, Sindh; (22) Dr M Arif N Saqib, Senior Research Officer, Pakistan Health Research 
Council, Islamabad, Punjab; (23) Dr Pir Alam Said, Medical Specialist DHQ, Sawabi, Khyber Pakhtunkhwa; (24) Professor Abrar Shaikh, Head Department of Medicine, Ghulam Muhammad Mahar Medical College, Sukkur, Sindh; (25) Mr Bilal Tahir, NDSP Coordinator, Baqai Institute of Diabetology and Endocrinology, Baqai Medical University, Karachi, Sindh; (26) Professor Salma Tanveer, Professor of Medicine, In-charge Diabetes and Endocrinology, Nishter Medical University, Multan, Punjab; (27) Professor Bilal Bin Younus, Head of Sakeena Institute of Diabetes \& Endocrine Research, Lahore, Punjab; (28) Professor Jamal Zafar, Professor of Medicine, Pakistan Institute of Medical Sciences, Islamabad, Punjab.

Contributors $\mathrm{AB}$ : concept, design, interpretation of data, wrote and approved the final submitted version. AF: concept, design, literature search, designing quality assurance measures, research data, wrote and approved the final submitted version. $\mathrm{HQ}$ : involved in the quality control, edited and approved the final submitted version. ASS: concept, design and involved in the quality control. NDSP members were responsible for the supervision of the survey, concept, design, involved in the quality control and data management in their respective areas. All members approved the final submitted version. $\mathrm{AB}$ and $\mathrm{AF}$ are the guarantors and undertake the full responsibility for the contents of the article submitted for publication.

Funding Haemoglobin A1cs and lipid profiles were performed by Pakistan Health Research Council (PHRC). Field visits and data collection including clinical and anthropometric measurements and also fasting plasma glucose and 2-hour post/glucose load samples were run by the respective teams through their own funds. The whole survey was coordinated and supported by the Baqai Institute of Diabetology \& Endocrinology (BIDE) on their own resources.

Competing interests None declared.

Patient consent Obtained.

Ethics approval National Bioethics Committee (NBC) of Pakistan (Ref: No.4-87/17/ NBC-226/NBC/2664).

Provenance and peer review Not commissioned; externally peer reviewed.

Data sharing statement No additional data are available.

Open access This is an open access article distributed in accordance with the Creative Commons Attribution Non Commercial (CC BY-NC 4.0) license, which permits others to distribute, remix, adapt, build upon this work non-commercially, and license their derivative works on different terms, provided the original work is properly cited, appropriate credit is given, any changes made indicated, and the use is non-commercial. See: http://creativecommons.org/licenses/by-nc/4.0/.

\section{REFERENCES}

1. Ogurtsova K, da Rocha Fernandes JD, Huang Y, et al. IDF Diabetes Atlas: Global estimates for the prevalence of diabetes for 2015 and 2040. Diabetes Res Clin Pract 2017;128:40-50.

2. Shaw JE, Sicree RA, Zimmet PZ. Global estimates of the prevalence of diabetes for 2010 and 2030. Diabetes Res Clin Pract 2010;87:4-14.

3. World Health Organization. Global report on diabetes, 2016.

4. International Diabetes Federation (IDF). Atlas. 7th edn, 2015.

5. World Health Organization (WHO) South/East Asia Diabetes fact sheet. Fact Sheet - NCD (Diabetes), Department of Sustainable Development and Healthy Environments, 2014.

6. Narayan KM, Zhang P, Williams D, et al. How should developing countries manage diabetes? CMAJ 2006;175:733-6.

7. Shera AS, Jawad F, Maqsood A. Prevalence of diabetes in Pakistan. Diabetes Res Clin Pract 2007;76:219-22.

8. Shera AS, Rafique G, Khwaja IA, et al. Pakistan national diabetes survey: prevalence of glucose intolerance and associated factors in Shikarpur, Sindh Province. Diabet Med 1995;12:1116-21.

9. Shera AS, Basit A, Fawwad A, et al. Pakistan National Diabetes Survey: prevalence of glucose intolerance and associated factors in the Punjab Province of Pakistan. Prim Care Diabetes 2010;4:79-83.

10. Shera AS, Rafique G, Khawaja IA, et al. Pakistan National Diabetes Survey: prevalence of glucose intolerance and associated factors in Baluchistan province. Diabetes Res Clin Pract 1999;44:49-58.

11. Shera AS, Rafique G, Khwaja IA, et al. Pakistan National Diabetes Survey prevalence of glucose intolerance and associated factors in North West at Frontier Province (NWFP) of Pakistan. J Pak Med Assoc 1999;49:206-11.

12. Basit A, Danish Alvi SF, Fawwad A, et al. Temporal changes in the prevalence of diabetes, impaired fasting glucose and its associated risk factors in the rural area of Baluchistan. Diabetes Res Clin Pract 2011;94:456-62.
13. Misra A, Vikram NK, Sharma R, et al. High prevalence of obesity and associated risk factors in urban children in India and Pakistan highlights immediate need to initiate primary prevention program for diabetes and coronary heart disease in schools. Diabetes Res Clin Pract 2006;71:101-2.

14. Non/communicable diseases (NCDs) Risk factors survey Pakistan. https://www.dropbox.com/s/j72r5c8ylm49rq3/NON\% 20Communicable\%20Diseases $\% 20$ Risk\%20Factors $\% 20$ Survey\% 20Pakistan.pdf?dl=0 (assessed11 Oct 2017)

15. Zafar J, Bhatti F, Akhtar N, et al. Prevalence and risk factors for diabetes mellitus in a selected urban population of a city in Punjab. J Pak Med Assoc 2011;61:40-7.

16. Zafar J, Nadeem D, Khan SA, et al. Prevalence of diabetes and its correlates in urban population of Pakistan: A Cross-sectional survey. J Pak Med Assoc 2016;66:922-7.

17. International Institute for Population Sciences (IIPS) and Macro International. National Family Health Survey (NFHS-3). Mumbai: IIPS, 2007:2005-6.

18. Pakistan Bureau of Statistics. Population Census. 2017. http://www. pbscensus.gov.pk/sites/default/files/Population_Results.pdf

19. Multiple indicator cluster survey manual. Chapter 4: Designing and selecting the sample. mics.unicef.org/files?job.sha= 3d97a05358bb0e37 (assessed 12 Oct 2017).

20. Harrison GG, Buskirk ER, Lindsay Carter JE, et al. Skinfold thickness and measurement technique. In: Lohman TG, Roche AF, Martorell R, eds. Anthropometric standardization reference manual. Champaign: Human Kinetics Books, 1988:55-70.

21. Fawwad A, Sabir R, Riaz M, et al. Measured versus calculated LDL-cholesterol in subjects with type 2 diabetes. Pak J Med Sci 2016;32:955-60.

22. World Health Organization. Good laboratory practice training manual for the trainer: a tool for training and promoting good laboratory practice (GLP) concepts in disease endemic countries - 2 ed, 2008. http://www.who.int/tdr/publications/documents/glp-trainer.pdf (assessed12 Nov 2017)

23. World Health Organization. Definition and diagnosis of diabetes mellitus and intermediate hyperglycemia: report of a WHO/IDF consultation, 2006.

24. American Diabetes Association (ADA). Standards of medical care in diabetes-2016. Diabetes Care 2016;39:S1-S106.

25. WHO Western Pacific Region, International Association for the Study of Obesity, International Obesity Task Force. The Asia Pacific perspective: redefining obesity and its treatment. Health Communications Australia Pty Limited: St Leonards, 2000.

26. Expert Panel on Detection, Evaluation, and Treatment of High Blood Cholesterol in Adults. Executive summary of the third report of the national cholesterol education program (ncep) expert panel on detection, evaluation, and treatment of high blood cholesterol in adults (adult treatment panel iii). JAMA 2001;285:2486-97.

27. Cochran WG. Sampling techniques. Canada: John Wiley and Sons, 1977.

28. Ali O, Tan TT, Sakinah O, et al. Prevalence of NIDDM and impaired glucose tolerance in aborigines and Malays in Malaysia and their relationship to sociodemographic, health, and nutritional factors. Diabetes Care 1993;16:68-75.

29. Rahim MA, Hussain A, Azad Khan AK, et al. Rising prevalence of type 2 diabetes in rural Bangladesh: a population based study. Diabetes Res Clin Pract 2007;77:300-5

30. Satman I, Yilmaz T, Sengül A, et al. Population-based study of diabetes and risk characteristics in Turkey: results of the turkish diabetes epidemiology study (TURDEP). Diabetes Care 2002;25:1551-6.

31. Xu Y, Wang L, He J, et al. China Non communicable Disease Surveillance Group. Prevalence and control of diabetes in Chinese adults. JAMA 2013;310:948-59.

32. Anjana RM, Deepa M, Pradeepa R, et al. Prevalence of diabetes and prediabetes in 15 states of India: results from the ICMR-INDIAB population-based cross-sectional study. Lancet Diabetes Endocrinol 2017;5:585-96.

33. Sharma M, Nazareth I, Petersen I. Trends in incidence, prevalence and prescribing in type 2 diabetes mellitus between 2000 and 2013 in primary care: a retrospective cohort study. BMJ Open 2016;6:e010210.

34. Mainous AG, Tanner RJ, Baker R, et al. Prevalence of prediabetes in England from 2003 to 2011: population-based, cross-sectional study. BMJ Open 2014;4:e005002.

35. Zhou X, Pang Z, Gao W, et al. Performance of an A1C and fasting capillary blood glucose test for screening newly diagnosed diabetes and pre-diabetes defined by an oral glucose tolerance test in Qingdao, China. Diabetes Care 2010;33:545-50. 
36. Lorenzo C, Wagenknecht LE, Hanley AJ, et al. A1C between 5.7 and $6.4 \%$ as a marker for identifying pre-diabetes, insulin sensitivity and secretion, and cardiovascular risk factors: the Insulin Resistance Atherosclerosis Study (IRAS). Diabetes Care 2010;33:2104-9.

37. Fawwad A, Alvi SF, Basit A, et al. Changing pattern in the risk factors for diabetes in young adults from the rural area of Baluchistan. J Pak Med Assoc 2013;63:1089-93.
38. Basit A, Hydrie MZI, Ahmed K, et al. impaired fasting glucose and associated risk factors in a rural area of Baluchistan according to new ADA criteria. J Pakistan Med Assoc 2002;52:357-60.

39. Saleem F, Dua JS, Hassali AA, et al. Hypertension in Pakistan: time to take some serious action. Br J Gen Pract 2010;60:449-50. 
Correction: Prevalence of diabetes, pre-diabetes and associated risk factors: second National Diabetes Survey of Pakistan (NDSP), 2016-2017

Basit A, Fawwad A, Qureshi H NDSP Members, et al. Prevalence of diabetes, pre-diabetes and associated risk factors: second National Diabetes Survey of Pakistan (NDSP), 20162017. BMJ Open 2018;8:e020961. doi: 10.1136/bmjopen-2017-020961.

The previous version of this manuscript contains incorrect versions of figures 2 and 3 in the published article. Figures 2 and 3 should appear as:

Figure 2: Age-stratified prevalence of diabetes among men and women with urban and rural distribution

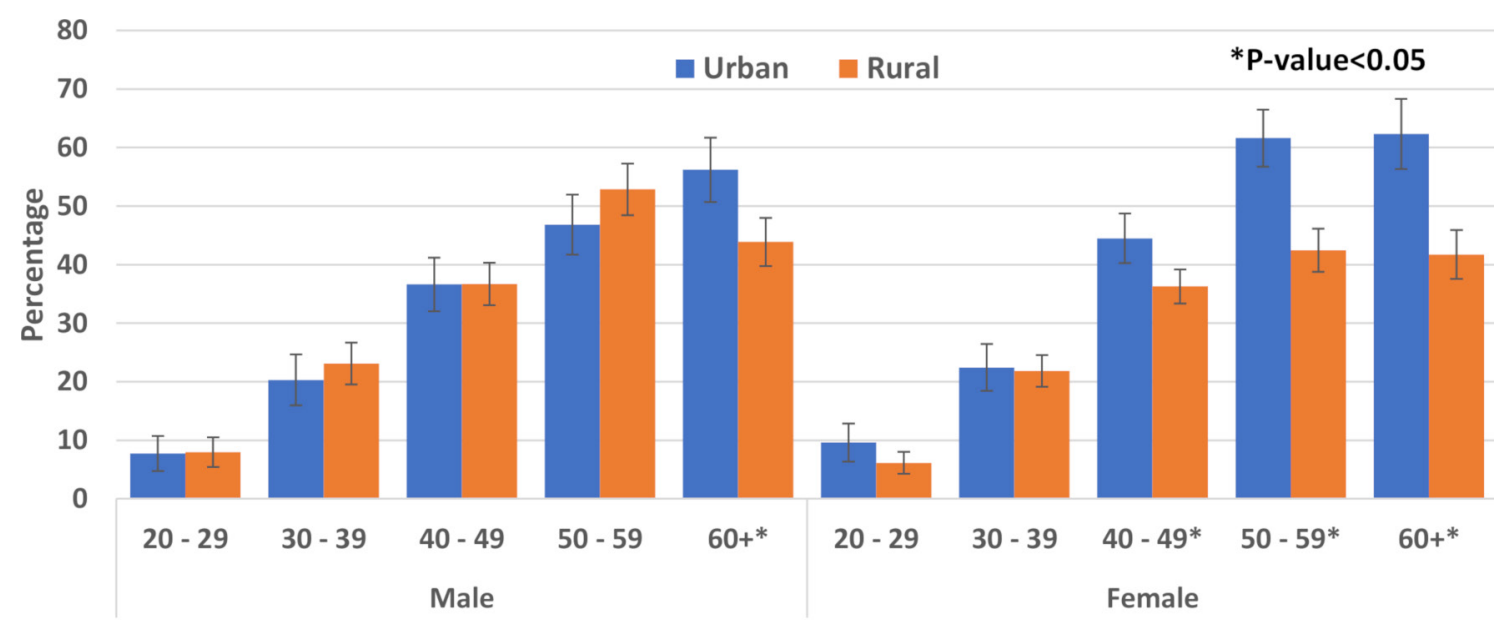

Age category

Figure 3: Age-stratified prevalence of pre-diabetes among men and women with urban and rural distribution

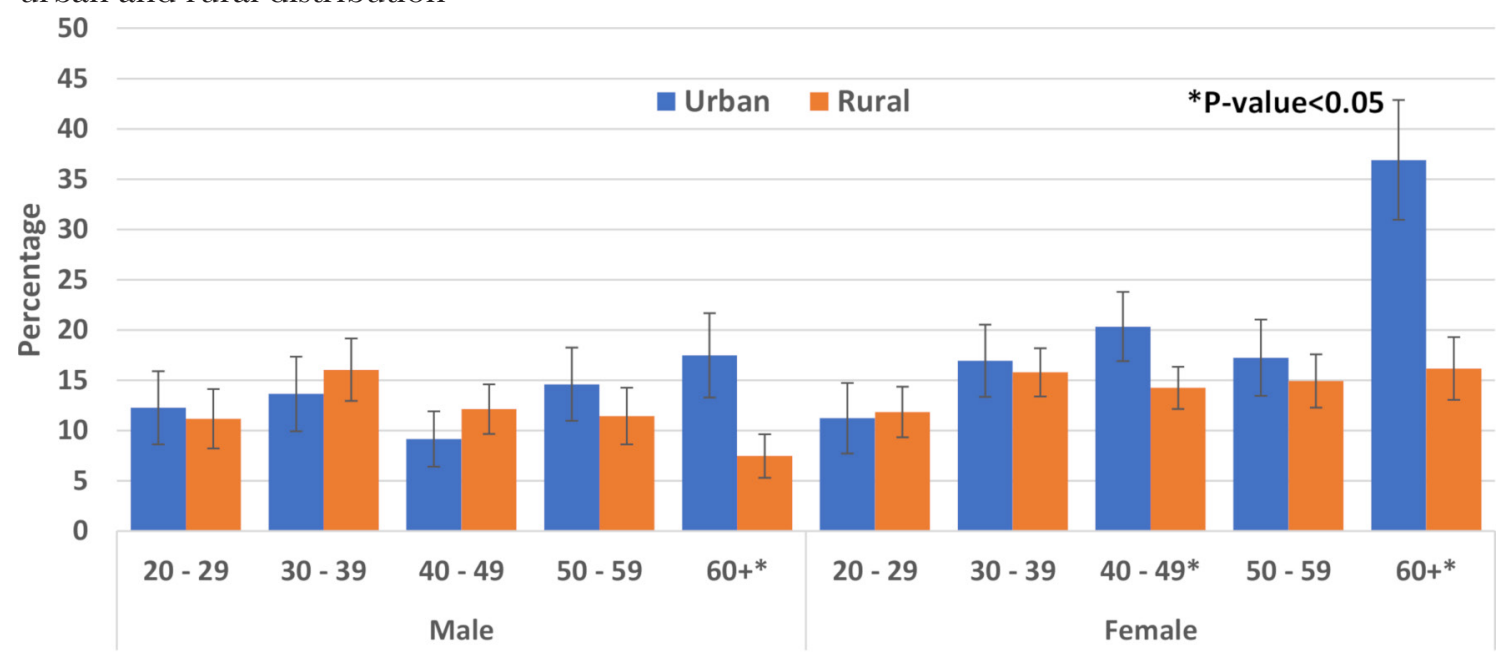

Age Category

The following related text should read as:

Urban women showed significantly higher prevalence of diabetes than rural women above the age of 40 years while in men this trend was seen in the age group of 60 years and above $(\mathrm{p}<0.05)$ (figure 2$)$. 
Relating to figure 3, the following text should read as:

Urban men showed significantly higher prevalence of pre-diabetes than rural men for the age group of 60 years and above while for women significant difference was seen in urban compared with rural population for the age groups of 40-49 and 60 years and above (figure 3 ).

Open access This is an open access article distributed in accordance with the Creative Commons Attribution Non Commercial (CC BY-NC 4.0) license, which permits others to distribute, remix, adapt, build upon this work non-commercially, and license their derivative works on different terms, provided the original work is properly cited, appropriate credit is given, any changes made indicated, and the use is non-commercial. See: http://creativecommons.org/licenses/by-nc/4.0/.

(c) Author(s) (or their employer(s)) 2018. Re-use permitted under CC BY-NC. No commercial re-use. See rights and permissions. Published by BMJ.

BMJ Open 2018;0:e20961corr1. doi:10.1136/bmjopen-2017-020961corr1

A) Check for updates 